\title{
ABSTRAK \\ PENGARUH E-SER VICE QUALITY DAN HARGA TERHADAP KEPUASAN PELANGGAN PERUSAHAAN JASA PENGIRIMAN PAKET DI KARAWANG
}

Oleh :

\author{
Citra Savitri 1
}

Aji Tuhagana 2

\author{
Program Studi Manajemen FBIS Universitas Buana Perjuangan Karawang \\ Email: citra.savitri@ubpkarawang.ac.id \\ Aji.tuhagana@ubpkarawang.ac.id
}

Perkembangan internet telah membawa banyak perubahan dalam aspek kehidupan manusia. Internet membuat semua menjadi lebih mudah dan cepat, perkembangan internet yang turut di imbangi perkembangan teknologi membuat hal- hal dalam kehidupan manusia lebih cepat dan mudah indonesia merupakan negara yang turut merasakan perkembangan tersebut,pengguna internet terus mengalami peningkatan setiap harinya.

Penelitian ini bertujuan untuk mengetahui besarnya pengaruh e-service quality, harga dan kepuasan pelanggan pada Perusahaan Jasa khususnya Jasa pengiriman paket.

Metode penelitian menggunakan metode deskriptif dan verifikatif. Sampel dikumpulkan dengan menggunakan metode Sample Random Sampling dengan jumlah sampel sebanyak 30 orang pengguna jasa pengiriman paket. Teknik analisis menggunakan Teknik sampling yang gunakan adalah non random sampling dengan teknik Sratified Proporsional Random Sampling menggunakan analisis linier berganda dan SPSS Statistics versi 23.

Hasil penelitian diperoleh berdasarkan analisis deskriptif menunjukkan bahwa variabel e-service quality berpengaruh positif terhadap kepuasan pelanggan. Berdasarkan analisis verifikatif membuktikan bahwa "e-service quality dan harga berpengaruh positif secara bersama-sama terhadap kepuasan pelanggan". Besarnya pengaruh e-service quality dan harga terhadap kepuasan pelanggan sebesar 0,278 atau 27,8\% artinya bahwa besarnya pengaruh variabel $e$ service quality dan harga terhadap kepuasan pelanggan sebesar $27,8 \%$ sedangkan $72,2 \%$ dipengaruhi oleh variabel lain yang tidak diteliti dalam penelitian ini.

\section{Kata Kunci : E-service quality, Harga, Kepuasan Pelanggan}




\section{PENDAHULUAN}

Perkembangan internet telah membawa banyak perubahan dalam aspek kehidupan manusia. Internet membuat semua menjadi lebih mudah dan cepat, perkembangan internet yang turut di imbangi perkembangan teknologi membuat hal- hal dalam kehidupan manusia lebih cepat dan mudah indonesia merupakan negara yang turut merasakan perkembangan tersebut,pengguna internet terus mengalami peningkatan setiap harinya. Awal januari 2017 dari total populasi penduduk indonesia sebesar 262 juta penduduk (https://databoks.katadata.co.id) diketahui pengguna internet di Indonesia 132,7 juta dengan peningkatan pengguna sebesar 51\% dari tahun 2016 dimana pengguna internet sebesar 88,1 juta dari total 259,1 juta penduduk Indonesia (https://chaerulyamin.blogspot.com).

Jasa pengiriman barang merupakan suatu bentuk pelayanan yang menawarkan kemudahan dalam proses mengirim suatu barang dari satu kota ke kota lainnya dengan aman dan dapat di pertanggung jawabkan oleh pihak jasa tersebut. Pengiriman barang dapat berupa dokumen, logistik, produk elektronik dan lain-lain. Alat transportasi yang digunakan untuk mengirim barang dapat melalui jalur darat, laut maupun udara. Jarak menjadi begaian penting untuk mementukan alat transportasi apa yang akan di gunakan untuk mengangkut barang - barang tersebut.

Menggunakan teknologi internet dan akses internet dengan browser menggunakan koneksi data yang terhubung secara global mendukung masyarakat untuk mengakses informasi yang cepat dan mudah menggunakan perangkat komputer seperti laptop, tablet maupun smartphone, sehingga lewat teknologi sangat memudahkan pelanggan dalam mengetahui keberadaan, status, kemajuan/progres dari barang yang di kirim tersebut.

Adanya pelayanan elektronik ini diharapkan pelanggan tidak perlu takut dan khawatir mengenai barang yang dikirim melalui jasa pengiriman barang Jasa pengiriman paket karena dengan pelayanan elektronik ini pelanggan dapat melakukan monitoring progres dari barang yang dikirim terhitung sejak barang masuk kemudian di proses sampai ke tempat tujuan.

Adanya ketidakpastian waktu sampai pengiriman barang dengan waktu 
yang dijanjikan membuat pelanggan merasa kurang puas dimana estimasi yang di tentukan misalnya 3-4 hari namun barang sampai tujuan lebih dari 4 hari itu artinya membuat rasa kepuasan dalam diri pelanggan menurun. Lalu pelanggan tidak tahu detail tracking barang yang di kirim telah sampai mana, itu membuat pelanggan bingung dan cemas terhadap barang kirimannya. Berikut jumlah pelanggan yang komplain pada Jasa pengiriman paket Di karawang pada bulan Desember 2018 :

Tabel 1.1.

Jumlah Komplain Pelanggan

\begin{tabular}{|c|c|c|}
\hline Bulan Desember & Jumlah pelanggan Komplain & Keterangan Komplain \\
\hline Minggu Pertama & 3 Pelanggan & \multirow{4}{*}{ 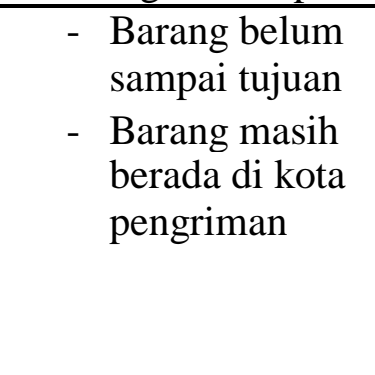 } \\
\hline Minggu Kedua & 2 Pelanggan & \\
\hline Minggu Ketiga & - & \\
\hline Minggu Keempat & 5 Pelanggan & \\
\hline
\end{tabular}

Sumber : Agen JASA PENGIRIMAN PAKET Di karawang 2018

Tabel diatas menunjukan bahwa setiap minggunya Agen JASA PENGIRIMAN PAKET Di karawang menerima komplain dari pelanggan dan jumlahnya pun tidak stabil kadang menerima komplain dengan jumlah banyak dan kadang pula dengan jumlah kecil bahkan ada di satu minggu itu tidak ada komplain sama sekali, alasan pelanggan komplain dengan berbagai keterangan mulai dari barang yang di belum sampai tujuan, sampai barang yang di kirim masih tetap berada daerah yang pelanggan kirim.

Kepuasan pelanggan adalah perasaan senang atau kecewa seseorang yang muncul setelah membandingkan antara harapan terhadap kenyataan yang diperoleh menurut Kotler (2009). Indikator-indikator dalam kepuasan pelanggan adalah membeli/mengirim kembali, menciptakan word of mouth yaitu mengatakan hal-hal yang baik tentang perusahaan kepada orang lain, menciptakan citra merek, dan perilaku komplain yaitu pelanggan yang puas cenderung lebih kecil kemungkinannya melakukan komplain.

Faktor-faktor yang mempengaruhi kepuasan pelanggan adalah kualitas produk, harga, promosi, lokasi, dan kualitas pelayanan menurut Tjiptono 2015 
(dalam Primadiawan). Penelitian sebelumnya yang dilakukan oleh Rinawati (2009) yang berjudul Pengaruh kualitas produk, kualitas pelayanan, harga dan factor emotion terhadap kepuasan pasien rawat inap RSU Yogyakarta. Variabel yang digunakan adalah kualitas produk, kualitas pelayanan, harga dan factor emotion. Alat analisis yang digunakan adalah regresi linear berganda. Hasil penelitian menunjukan bahwa kualitas produk, kualitas pelayanan, harga dan factor emotion berpengaruh positif dan signifikan terhadap kepuasan pasien.

Kualitas pelayanan elektronik (elektronic service quality) menurut Tjiptono dan Chandra 2011 (dalam Pasha) diartikan sebagai model kualitas jasa online yang paling kompherensif dan integrative, karena dimensinya relevan dan secara menyeluruh memenuhi kebutuhan untuk mengevaluasi kualitas jasa elektronik.

Kualitas pelayanan elektronik atau e-service quality yang baik akan menimbulkan kepuasan kepada pelanggan. Kepuasan pelanggan merupakan faktor penentuan yang signifikan dari pengulangan pembelian, informasi dari mulut ke mulut. Oleh karena itu perusahaan harus lebih meningkatkan kualitas pelayanan secara elektronik atau e-service quality agar dapat meningkatkan kepuasan pelanggan pada jasa pengiriman barang Jasa pengiriman paket.

Pelanggan akan merasa puas terhadap layanan yang di berikan perusahaan jika mereka merasakan kualitas layanan yang mereka terima dan memenuhi harapan. Perusahaan yang dapat memberikan layanan yang berkualitas kepada pelanggan akan menimbulkan kepuasan pelanggan Siwantara, 2011(dalam Hansel).

Menurut Malik dkk 2012 (dalam Rahman dan Harti) sebagian besar harga sedang dinilai oleh konsumen sesuai dengan layanan kualitas yang pada gilirannya menciptakan kepuasan atau ketidakpuasan, yang tergantung pada prinsip ekuitas, konsumen ingin melakukan kesepakatan dengan penyedia layanan dalam kasus ketika harga sedang dirasakan oleh keadilan harga konsumen. Jadi harga berperan penting dalam mendapatkan kepuansan pelanggan. Jika harga yang di bayar pelanggan sesuai dengan waktu pengiriman yang di tentukan maka pelanggan akan merasa puas. Berikut harga ongkis kirim Jalur Nugraha Ekakuris (JASA PENGIRIMAN PAKET) dari Karawang ke Jakarta. 
Tabel 1.2

Daftar harga ongkos kirim Jasa pengiriman paket

\begin{tabular}{|c|c|c|c|}
\hline Service & Ongkos Kirim & Estimasi Waktu & Berat \\
\hline SS & 60.000 & Di tentukan oleh Pelanggan & Per jam \\
\hline YES & 18.000 & 1 Hari & Per 1 Kilogram \\
\hline REG & 11.000 & 2-3 Hari & Per 1 Kilogram \\
\hline OKE & 10.000 & 4-6 Hari & Per 1 Kilogram \\
\hline JTR & 25.000 & 10 Hari & Per 10 kilogram \\
\hline
\end{tabular}

Sumber: Agen JASA PENGIRIMAN PAKET Di karawang 2019

Tabel di atas menunjukan bahwa harga yang di bayar pelanggan dengan harga tinggi maka pengiriman barang akan sampai dengan cepat kepada daerah tujuannya, sebaliknya harga yang di bayar dengan harga murah maka barang akan sampai dengan waktu yang cukup lama, jika pelanggan membayar sesuai waktu pengiriman yang sudah di tentukan makan pelanggan pun akan merasa puas, maka dari itu harga sangat berpengaruh terhadap kepuasan pelanggan.

E-Service Quality dan harga yang baik akan mendukung perusahaan dalam memberikan pelayanan yang lebih baik lagi sehingga menciptakan kepuasan pada pelanggan yang selanjutnya akan berpengaruh pada loyalitas terhadap perusahaan untuk meningkatkan jumlah pembelian dan menarik pelanggan baru, maka di perlukan analisis E-Servis Quality dan Harga terhadap Kepuasan Pelanggan.

Dari uraian di atas, maka penulis memutuskan untuk melakukan penelitian dengan judul : "Pengaruh E-Service Quality dan Harga terhadap Kepuasan Pelanggan (kasus pada pengguna JASA PENGIRIMAN PAKET Di karawang)”.

\section{KAJIAN PUSTAKA}

Menurut Kotler dan Keller 2013 (dalam Lorena) manajemen pada umumnya dikaitkan dengan aktivitas-aktivitas perencanaan, pengorganisasian, pengendalian, penempatan, pengarahan, motivasi, komunikasi, dan pengambilan keputusan yang dilakukan oleh setiap organisasi dengan tujuan untuk mengkoordinasikan berbagai sumber daya yang dimiliki oleh perusahaan sehingga akan dihasilkan suatu produk atau jasa secara efisien.

Manajemen adalah ilmu dan seni dalam perencanaan, pengorganisasian, 
pengarahan, pemotivasian, pengendalian terhadap orang dan mekanisme kerja untuk mencapai tujuan. Menurut Hery 2013 (dalam Lorena), manajemen adalah apa yang dilakukan oleh manajer, dengan kata lain manajemen merupakan proses mengkordinir kegiatan pekerjaan secara efektif dan efisien, dengan dan melalui orang lain.

Dapat disimpulkan bahwa, manajemen adalah kegiatan untuk mencapai dan memenuhi sasaran organisasi (efektivitas), tetapi juga menjalankan kegiatan tersebut se-efisien mungkin, efektifitas dan efisien dapat dicapai melalui fungsi manajemen yaitu planning, organizing, actuating, dan controling.

Pemasaran merupakan kegiatan penting yang harus dilakukan oleh sebuah perusahaan untuk mendapatkan keuntungan. Tanpa adanya kegiatan pemasaran, maka konsumen tidak akan mengetahui produk atau jasa yang ditawarkan oleh perusahaan. Kotler dan Keller (2009), mendefinisikan pemasaran adalah mengidentifikasi dan memenuhi kebutuhan manusia dan sosial. Salah satu definisi yang baik dan singkat dari pemasaran adalah "memenuhi kebutuhan dengan cara yang menguntungkan".

\section{Pengertian E-Service Quality}

Menurut Hsin Hsin Chang,et al., 2009 (dalam Nurrizal) bahwa e-service dapat didefinisikan sebagai layanan website yang memfasilitasi pelanggan dalam berbelanja, membeli, dan memberikan produk secara efisien dan efektif. Seperti yang ada dalam definisi di atas, arti dari layanan tersebut mencakup sebelum dan pada saat pelayanan pada website. Jika pelayanan elektronik sudah dapat di nikmati oleh pelanggan, pelanggan dapat menggunakan dengan mudah dan nyaman maka akan tercipta suatu kepuasan yang akan di rasakan oleh pelanggan pada layanan elektronik yang di diberikan oleh perusahaan.

Terdapat perbedaan perilaku pembelian antara pembelian melalui internet dengan pembelian langsung. Pembelian melalui internet dapat dipengaruhi oleh layanan langsung yang dirasakan ketika mencari informasi dan transaksi maupun komunikasi yang berlangsung. Pembelian melalui internet dipengaruhi oleh kualitas layanan melalui internet (e-service) yang di rasakan oleh pelanggan. Penelitian 
mengenai pembelian melalui layanan internet menghasilkan sejumlah temuan penting yang bermanfaat bagi pemasar untuk meningkatkan daya tarik masyarakat dalam berbelanja online dan kepuasan membeli melalui online. (Tatik Suryani, 2013 (dalam Nurrizal).

Menurut Tjiptono dan Chandra , 2016 (dalam Lorena) terdapat lima dimensi utama kualitas pelayanan yang disusun sesuai dengan urutan tingkat relatifnya.

1. Reliability (reliabilitas) berkaitan dengan kemampuan perusahaan untuk memberikan layanan yang akurat sejak pertama kali tanpa memberikan kesalahan apapun dan menyampaikan jasanya sesuai waktu yang disepakati.

2. Daya tangkap (responsiveness), berkenaan dengan kesediaan dan kemampuan para karyawan membantu para karyawan dan merespon permintaan mereka, serta menginformasikan kapan jasa akan diberikan dan kemudian memberikan jasa secara cepat.

3. Jaminan (assurance) yakni perilaku para karyawan mampu menumbuhkan kepercayaan pelanggan terhadap perusahaan dan perusahaan bisa menciptakan rasa aman bagi para pelanggannya

4. Empati (emphaty), berarti bahwa perusahaan memahami masalah para pelanggannya dan bertindak demi kepentingan pelanggan, serta memberikan perhatian personal kepada para pelanggan dan memiliki jam operasional yang nyaman

5. Bukti fisik (tangibles), berkenan dengan daya tarik fasilitas fisik, perlengkapan dan material yang digunakan perusahaan serta penampilan karyawan.

Menurut Zeithaml et al, 2009 (dalam Tobagus) dalam bukunya membedakan ke-tujuh dimensi $e$-service quality menjadi empat dimensi inti yang digunakan pelanggan untuk menilai situs web dimana mereka tidak mengalami pertanyaan atau masalah adalah :

1. Efficiency, kemudahan dan kecepatan mengakses dan menggunakan situs.

2. Fullfillment, sejauh mana janji situs tentang ketersediaan pesanan dan ketersediaan item terpenuhi. 
3. System availability, kebenaran fungsi teknis dari situs.

4. Privacy, sejauh mana situs tersebut aman dan melindungi informasi pengguna.

\section{Harga}

Menurut Kotler dan Keller (2009) harga adalah salah satu elemen bauran pemasaran yang menghasilkan pendapatan dan harga merupakan elemen termudah dalam program pemasaran untuk disesuaikan, fitur produk, saluran dan bahkan komunikasi membutuhkan lebih banyak waktu. Menurut Kotler dan Armstrong, 2010 (dalam Primadiawan) harga adalah sejumlah uang yang dibebankan atas suatu produk atau jasa atau jumlah dari nilai yang ditukar pelanggan atas manfaat-manfaat karena memiliki atau menggunakan produk atau jasa tersebut. Dari kedua definisi tersebut menjelaskan bahwa harga adalah unsur penting dalam sebuah perusahaan di mana dengan adanya harga maka perusahaan akan mendapatkan income bagi keberlangsungan perusahaan. Selain itu, harga juga merupakan alat yang nantinya dijadikan proses pertukaran terhadap suatu barang atau jasa oleh pelanggan.

\section{Kepuasan Pelanggan}

Menurut Kotler dan Keller (2009) kepuasan pelanggan adalah perasaan senang atau kecewa seseorang yang muncul setelah membandingkan antara harapan terhadap kenyataan yang diperoleh. Kepuasan atau rasa senang yang tinggi menciptakan ikatan emosional dengan merek atau perusahaan yang bersangkutan. Sedangkan menurut Tjiptono dan Diana, 2015 (dalam Primadiawan) Kepuasan pelanggan adalah perasaan senang atau kecewa yang didapatkan seseorang dari membandingkan antara kinerja atau hasil produk atau jasa yang di persepsikan dan ekspetasinya.

\section{Konsekuensi Kepuasan Pelanggan}

Menurut Tjiptono, 2015 (dalam Primadiawan) berbagai riset kepuasan pelanggan selama ini mengindentifiikasikan bahwa kepuasan pelanggan berdampak signifikan pada sejumlah aspek berikut: 
a. Niat beli ulang

Yaitu pelanggan puas cenderung berminat melakukan pembelian ulang produk atau jasa yang sama.

b. Loyalitas Pelanggan

Yaitu banyak riset yang menyimpulkan bahwa kepuasan pelanggan

berdampak positif bagi terciptanya loyalitas pelanggan.

c. Perilaku Komplain

Yaitu pelanggan yang puas cenderung lebih kecil kemungkinannya melakukan komplain.

d. Gethok Tular Positif

Yaitu kepuasan pelanggan berdampak positif pada kesediaan konsumen atau pelanggan untuk merekomendasikan produk atau jasa perusahaan kepada orang lain (gethok tular positif).

\section{Hipotesis Penelitian}

Berikut ini adalah hipotesis penelitian.

1. Terdapat pengaruh $e$-sevice quality terhadap kepuasan pelanggan pada pengguna Jasa pengiriman paket.

2. Terdapat pengaruh antara harga terhadap kepuasan pelanggan pada pengguna Jasa pengiriman paket.

3. Terdapat pengaruh antara -service quality dan harga terhadap kepuasan pelanggan pada pengguna Jasa pengiriman paket.

\section{METODE PENELITIAN}

. Metode penelitian yang digunakan dalam penelitian ini adalah metode deskriptif dan verifikatif.

Metode penelitian deskriptif adalah penelitian yang dilakukan untuk mengetahui keberadaan variabel mandiri, baik satu variabel atau lebih variabel (variabel yang berdiri sendiri) tanpa membuat perbandingan atau mencar hubungan variabel satu sama lain (Sugiyono, 2013) Metode ini untuk mengetahui: 
1. Bagaimana tanggapan konsumen mengenai e-service quality yang di berikan Jasa pengiriman paket

2. Bagaimana tanggapan konsumen mengenai harga yang diberikan berikan Jasa pengiriman paket

3. Bagaimana tingkat kepuasan konsumen di Jasa pengiriman paket.

Sedangkan metode penelitian verifikatif adalah metode penelitian yang bertujuan untuk mengetahui :

1. Hubungan antar dua variabel atau lebih. Metode ini pada dasarnya menguji hipotesis yang di lakukan melalui pengumpulan data dilapangan.

Tabel diatas menunjukkan nilai pearson corelation (rhitung) untuk setiap pertanyaan lebih besar dari $r_{\text {tabel }}$, yaitu berkisar antara 0,651 - 0,890. Jadi seluruh item pernyataan Kepuasan Pelanggan dalam instrumen penelitian dinyatakan valid, karena rhitung lebih besar dari $r_{\text {tabel }} 0,361$.

a. Uji Reliabilitas

Uji reliabilitas dalam penelitian ini menggunakan koefisien Cronbach's Alpha dengan bantuan SPSS versi 23. Pengujian reliabilitas ditunjukkan oleh koefisien Alpha Cronbach dan dapat diolah dengan bantuan SPSS. Apabila ada pernyataan yang memiliki nilai Croanbach Alpha if item deleted lebih besar daripada Croanbach Alpha maka pernyataan tersebut tidak reliabel dan harus dilakukan pengujian selanjutnya. Hasil pengujian dikatakan reliabel jika alpha croanbach > 0,6 dan nilai alpha croanbach lebih besar dari pada croanbach's alpha if item deleted (Sekaran, 2010).

a) Jika nilai $h \quad>$ dengan toleransi ketidaktelitian $(\alpha)$ sebesar $5 \%$ maka instrumen tersebut dikatakan reliabel.

b) Jika nilai $h<$ dengan toleransi ketidaktelitian $(\alpha)$ sebesar 5\% maka instrumen tersebut dikatakan tidak reliabel.

Berikut adalah hasil uji reliabilitas :

Hasil uji reliabilitas ini dilakukan dengan menggunakan Cronbach's Alpha. Dalam uji reliabilitas, suatu instrumen penelitian dapat diterima bila dalam kisaran 
Cronbach's Alpha > 0,70 s/d 0,90 di anggap baik atau reliabel serta dalam kisaran $>0,80 \mathrm{~s} / \mathrm{d} 1.00$ dianggap sangat baik atau sangat reliabel, adapun tabel hasil uji reliabilitas adalah sebagai berikut :

Tabel 3.4

Hasil Uji Reliabilitas E-Service Quality

Reliability Statistics

\begin{tabular}{|r|r|}
\hline \multicolumn{1}{|c|}{$\begin{array}{c}\text { Cronbach's } \\
\text { Alpha }\end{array}$} & N of Items \\
\hline, 933 & 15 \\
\hline
\end{tabular}

Sumber: Hasil Pengolahan Data Primer, 2019

Berdasarkan tabel 3.4 dapat disimpulkan bahwa instrumen variabel $E$ Service Quality ini dikatakan baik atau reliabel, dikarenakan nilai Cronbach's Alpha sebesar 0,933 dalam kategori > 0,80 s/d 1.00 dianggap sangat baik / sangat reliabel.

Tabel 3.5

Hasil Uji Reliabilitas Harga

Reliability Statistics

\begin{tabular}{|r|r|}
\hline $\begin{array}{l}\text { Cronbach's } \\
\text { Alpha }\end{array}$ & N of Items \\
\hline, 946 & 15 \\
\hline
\end{tabular}

Sumber: Hasil Pengolahan Data Primer, 2019

Berdasarkan tabel 3.5 dapat disimpulkan bahwa instrumen variabel harga ini dikatakan baik atau reliabel, dikarenakan nilai Cronbach's Alpha sebesar 0,946 dalam kategori > 0,80 s/d 1.00 dianggap sangat baik / sangat reliabel.

Tabel 3.6

Hasil Uji Reliabilitas Kepuasan Pelanggan

Reliability Statistics

\begin{tabular}{|r|r|}
\hline \multicolumn{1}{|c|}{$\begin{array}{c}\text { Cronbach's } \\
\text { Alpha }\end{array}$} & N of Items \\
\hline, 960 & 15 \\
\hline
\end{tabular}

Sumber: Hasil Pengolahan Data Primer, 2019 
Berdasarkan tabel 3.6 dapat disimpulkan bahwa instrumen variabel kepuasan pelanggan ini dikatakan baik atau reliabel, dikarenakan nilai Cronbach's Alpha sebesar 0,960 dalam kategori > 0,80 s/d 1.00 dianggap sangat baik / sangat reliabel.

\section{HASIL PENELITIAN DAN PEMBAHASAN}

\section{Pembahasan Hasil Analisis Data}

Berdasarkan hasil penelitian tentang "E-service quality dan Harga terhadap Kepuasan Pelanggan (Kasus Pada JASA PENGIRIMAN PAKET Di karawang Karawang)" diperoleh hasil sebagai berikut:

1. E-service quality berpengaruh terhadap kepuasan pelanggan

Hasil penelitian menunjukkan bahwa variabel e-service quality berpengaruh positif terhadap kepuasan pelanggan. Hal ini dibuktikan dengan hasil statistik uji t variabel e-service quality diperoleh nilai thitung sebesar 3,104 sedangkan besarnya tabel adalah 1,983 (3,104 > 1,983), signifikansi lebih kecil dari $0,005(0,002<0,05)$, dan koefisien regresi mempunyai nilai positif sebesar 0,369 maka hipotesis menyatakan bahwa e-service quality berpengaruh positif terhadap kepuasan pelanggan.

Kualitas pelayanan online dalam dunia virtual sangat diperlukan agar menciptakan kepuasan pelanggan. Kualitas pelayanan online JASA PENGIRIMAN PAKET dalam menyediakan pelacakan posisi barang, harga ongkos kirim, dan estimasi waktu pengiriman barang yang menunjang keseluruhan kualitas pelayanan online JASA PENGIRIMAN PAKET akan membuat konsumen merasa puas.

Pelacakan barang adalah salah satu e-service quality yang diberikan JASA PENGIRIMAN PAKET dimana pelanggan akan mengetahui dan memantau posisi barang yang akan kita kirim atau kita terima berada dimana, jadi pelanggan tidak perlu khawatir tentang keberadaan barang kirimannya. Sehingga pelanggan pun akan merasa puasa dengan pelayanan online yang diberikan oleh JASA PENGIRIMAN PAKET.

Hasil temuan pada penelitian ini dapat diinterpretasikan bahwa, semakin besar $e$-service quality JASA PENGIRIMAN PAKET yang diberikan kepada 
pelanggan, maka akan sangat mempengaruhi rasa kepuasan pelanggan. Tapi jika e-service quality dari JASA PENGIRIMAN PAKET mengalami penurunan, maka rasa kepuasan pelanggan akan mengalami penurunan pada e-service quality yang diberikan.

2. Harga berpengaruh terhadap kepuasan pelanggan

Hasil penelitian menunjukkan bahwa variabel harga berpengaruh positif terhadap kepuasan pelanggan. Hal ini dibuktikan dengan hasil statistik uji $t$ variabel harga diperoleh nilai thitung sebesar 5,392 sedangkan besarnya ttabel adalah $1,983(5,392>1,983)$, signifikansi lebih kecil dari $0,005(0,000<0,05)$, dan koefisien regresi mempunyai nilai positif sebesar 0,355 maka hipotesis menyatakan bahwa harga berpengaruh positif terhadap kepuasan pelanggan.

Harga yang ditawarkan JASA PENGIRIMAN PAKET cukup terjangkau untuk semua kalangan dan harga yang di tawarkan pun sesuai dengan berat barang dan kota yang di tuju dan itu semua membuat pelanggan puas karena harga yang diberikan JASA PENGIRIMAN PAKET cukup sesuai dengan manfaat yang diterima.

3. E-service quality dan harga berpengaruh terhadap kepuasan pelanggan Hasil statistik uji regresi linier berganda diperoleh F hitung sebesar 19,444 dengan nilai signifikansi 0,000 , karena nilai signifikansi lebih kecil dari $0,05(0,000$ $<0,05)$ maka penelitian ini berhasil membuktikan bahwa "e-service quality dan harga berpengaruh positif secara bersama-sama terhadap kepuasan pelanggan". Besarnya pengaruh e-service quality dan harga terhadap kepuasan pelanggan sebesar 0,278 atau 27,8\% artinya bahwa besarnya pengaruh variabel e-service quality dan harga terhadap kepuasan pelanggan sebesar $27,8 \%$ sedangkan $72,2 \%$ dipengaruhi oleh variabel lain yang tidak diteliti dalam penelitian ini.

\section{KESIMPULAN DAN SARAN}

\section{Kesimpulan}

Berdasarkan data yang didapatkan dan pengujian yang telah dilakukan terhadap permasalahan, maka dapat diambil kesimpulan sebagai berikut : 
1. E-Service Quality berpengaruh secara signifikan terhadap Kepuasan Pelanggan JASA PENGIRIMAN PAKET Di karawang.

2. Harga berpengaruh secara signifikan terhadap Kepuasan Pelanggan JASA PENGIRIMAN PAKET Di karawang.

3. E-Service Quality dan Harga berpengaruh secara signifikan terhadap Kepuasan Pelanggan JASA PENGIRIMAN PAKET Di karawang.

\section{Saran}

Berdasarkan keterbatasan penelitian yang dilakukan, penulis menyampaikan beberapa saran sebagai berikut :

1. Sebaiknya Agen JASA PENGIRIMAN PAKET Di karawang lebih meningkatkan lagi situs pengecekan barang agar lebih mudah di pahami pelanggan dan membuat pelanggan merasa puas.

2. Sebaiknya Agen JASA PENGIRIMAN PAKET Di karawang lebih meningkatkan pelayanan dalam hal pengiriman barang yang sampai tepat waktu.

3. Sebaiknya Agen JASA PENGIRIMAN PAKET Di karawang memberikan pelatihan kepada karyawan agar pelayanan yang diberikan kepada pelanggan lebih baik dan membuat pelanggan merasa puas terhadap Agen JASA PENGIRIMAN PAKET Di karawang.

4. Sebaiknya Agen JASA PENGIRIMAN PAKET Di karawang lebih meningkatkan perhatian dan memahami kebutuhan pelanggan agar pelanggan tersebut merasa puas dan merekomendasikan kepada orang lain agar menggunakan jasa perngiriman tersebut 
Adi, A.F.R. 2012, Analisis Pengaruh Harga, Kualitas Produk, dan Kualitas Layanan Terhadap Kepuasan Pelanggan. Jurnal Ekonomi dan Bisnis.Hal: 27-32

Amanah, D. 2010. "Pengaruh harga dan kualitas produk terhadap kepuasan konsumen pada Majestyk Baakery \& Cake Shop Cabang H.M Yamin Medan”. Jurnal EMBA. Vol. 2, No. 1: hal. 71-82

Amelisa Lisa, Yonaldi Sepris, dan Mayasari Hesti. 2016. “Analisis Pengaruh Kualitas Produk dan Harga terhadap Keputusan Pembelian Gula Tebu". Jurnal Manajemen dan Kewirausahaan, Vol. 7, No.3

Bimo, Aryo Swadono. 2013. “Pengaruh Fasilitas, Kualitas Pelayanan, dan Harga Tiket Terhadap Kepuasan Pelanggan Pengguna Jasa Transportasi Bus Antar Kota Antar Provinsi Sumber Alam”. Skripsi. Yogyakarta: Fakultas Ekonomi Universitas Sanata Dharma.

Cristobal, Eduard ,Carlos Flavia dan Miguel Guinali. 2007. Perceived e-service quality (PeSQ)Measurement validation and effects on consumer satisfaction and web site loyalty, Vol. 17 No. 3,pp. 317-340

Christian. G. 1984. A service Quality Modal and Its Marketing Implications. European Journal of Marketing, Vol. 18, No. 4, pp. 35-44 Hatane Samuel dan Nadya Wijaya. (2009).

Danang Darunanto. 2016. Pengaruh Harga dan Kualitas Pelayanan terhadap Kepuasan Pelanggan PT. DMS TOUR AND TRAVEL. Jurnal Manajemen Bisnis Transportasi dan Logistik Vol.2 No.2.

Databoks, (2018, 12 Januari). Jumlah Penduduk Indonesia. (https://databoks.katadata.co.id).

Ertika Grismartanti. 2015. Pengaruh Harga dan Kualitas Pelayanan terhadap Kepuasan Pelanggan PT. FULMOON EXPRESS TOUR AND TRAVEL. Jurnal Ekonomi dan Manajemen dan Akuntansi Vol.3 No.3.

Ghozali. Moch. 2014. Pengaruh Kualitas Pelayanan dan Harga Terhadap Kepuasan Pelanggan pada Expedisi Surabaya. Surabaya: STIESIA Jurnal Ilmu dan Riset Manajemen Vol.3.

Hatane Semuel \& Nadya Wijaya. 2009. "Service Quality, Perceive Value, Satisfaction, Trust dan Loyalty pada PT. Kereta Api Indonesia Menurut 
Penilaian Pelanggan Surabaya". Jurnal Manajemen Pemasaran Vol : 4 (1). Hal 23-37.

Hendra, Dimas (2018, 24 Februari). JASA PENGIRIMAN PAKET Targetkan Pertumbuhan 30\% di 2018. Dikutip 3 Januari 2019. www.swa.co.id.

Hui Yen,Chia dan Peng Lu, Hsi.2008. Effects Of E-Service Quality On Loyalty Intention: An Empirical Study In Online Auction,Vol 18 no 2, pp 127-146

Jahanshahi, Asghar Afshar., Gashti, Mohammad Ali Hajizadeh., Mirdamadi, Seyed Abbas., Nawaser, Khaled., Khaksar, Seyed Mohammad Sadeq. 2011. "Study the Effect of Customer Service and Product Quality on Customer Satisfaction and Loyalty". International Journal of Humanities and Social Science. Vol.1 No.7, 2011, 253-260.

Jotathan, Hansel. 2013. “Analisis Pengaruh E-Service Quality Terhadap Customer Satisfaction Yang Berdampak Pada Customer Loyalty Pt Bayu Buana Travel Tbk", Vol 14 No 2,pp 104-112

Kotler dan Keller. 2009. Manajemen Pemasaran. Jilid I. Edisi ke 13 Jakarta: Erlangga.

Lorena, Sepni. 2018. "Pengaruh E-Service Quality terhadap E-Satisfaction yang berdampak pada E-Loyalty. Lampung. Universitas Lampung.

Malik, Muhammad Ehsan., Ghafoor, Muhammad Mudasar., Iqbal, Hafiz Kashif. 2012. "Impact of Brand Image, Service Quality and Price On Customer Satisfaction in Pakistan Telecommunication Sector". International Journal of Business and Social Science, Vol.3 No.23, Desember 2012, 123-129.

Nurrizal, Muhammad. 2015. "Pengaruh E-Service Quality dan Kepuasan Pelanggan terhadap Loyalitas dengan Moderasi Persepsi Nilai yang Dirasakan Pelanggan Kereta Api di Surabaya"

Parasuraman, A.; V.A. Zeithaml; \& L.L. Berry.1988. SERVQUAL: A Multiple Item Scale for Measuring Consumen Perceptions of service Quality. Journal of Retailing, Vol 64.

Pasha, F.M.F. 2017. "Membangun Loyalty Intention melalui E-Service Quality dan Customer Satisfaction" Surakarta. Institus Agama Islam Negeri Surakarta.

Prasetio, A "Pengaruh Kualitas Pelayanan Dan Harga Terhadap Kepuasan Pelanggan” Jurnal Manajemen. Vol.1 No 4. 
Primadiawan, Ignatius A.P. 2018. "Pengaruh Kualitas Pelayanan dan Harga terhadap Kepuasan Pelanggan Bus PO IKA"

Rahman F.Y. Harti. "Pengaruh Kualitas Layanan dan Harga terhadap Kepuasan Konsumen di Wisata Kolam Renang Teuku Umarbojonegoro. Surabaya. Universitas Negeri Surabaya.

Ramadani, Yuda, dan Mintarti Rahayu. 2014. Pengaruh Kualitas Pelayanan, Harga dan Kepuasan Pelanggan terhadap Loyalitas Pelanggan (Studi pada PT. TIKI Jalur Nugraha Ekakurir Agen Galunggung Kota Malang). Jurnal Ilmiah Mahasiswa FEB. Vol. 2 No. 2.

Rinawati. 2009. "Pengaruh kualitas produk, kualitas pelayanan, harga dan factor emotion terhadap kepuasan pasien rawat inap RSU Yogyakarta.

Robinette, S \& Brand C., 2009, Emotion Marketing: The Hallmark Way of Winning Customers for Life, New York: The Free Press.

Tobagus, Anita. 2018. "Pengaruh E-Service Quality terhadap E-Satisfaction pada Pengguna di Situs Tokopedia" Agora Vol.6, No.1. 1, (2018) 1-10.

Yamin, Chaerul. (2016, 9 Mei). Statistik Penggunaan Internet di Indonesia. Dikutip 3 Januari 2019. https://chaerulyamin.blogspot.com. 